\section{Clinical Experience with the Dalkon Shield}

SIR,-Dr. J. S. Templeton (8 September, p. 542 ) is understandably disappointed at the results obtained with the Dalkon Shield at Southampton by $\mathrm{Mr}$. R. W. Jones and his colleagues (21 July, p. 143), and claims that multicentre studies for I.U.C.D. assessment should be obligatory in that overall figures for acceptability and reliability for any particular device can be better gauged by such studies.

I would take issue with this and argue that from a clinician's point of view the main advantage of a multicentre report is that it underlines the range of the results which are obtained. Thus Snowden and Williams found with the Dalkon Shield a pregnancy rate per 100 users after nine months of use which varied between 0.8 and 8.4 . Likewise, Tietze and Lewit, ${ }^{2}$ studying the $\mathrm{T} \mathrm{Cu} 200$ device in nine clinics found an overall pregnancy rate of 2.2 per 100 users, but at one centre the rate was 11.8

Bernard $^{3}$ and Snowden ${ }^{4}$ have investigated the reason for the marked discrepancy in results for the same device and have identified many factors. Some appear to be related to the doctor's skill and experience, others are patient-related-for example, her age, parity, religion, and use or not of additional contraceptive precautions. When choosing an I.U.C.D. for a particular patien the doctor should beware of relying too heavily on published data for overall device reliability.-I am, etc.,

St B rtholore: 's Hospital

Patricia Last

London E.C. 1

Snowden, R., and Williams, M., Contraception, Tietze, C., and Lewit, S., Studie: in Family Planning, 1972, 3, 277.

. American fournal of Public

gress Series, 1972, 260, 74.
.

\section{The Doctor's Attitude}

SIR,-In your discussion of the association between the social attitudes of psychiatrists and the treatments they recommend (29 September, p. 653) you point to the fact that such preferences are not based on reason alone but stem in part from deeper roots. There seems to be a remarkable consistency here that cuts across professional roles. My colleagues and I have found correlational similarities in a number of studies of nursing staff and psychiatric patients as well as doctors."-1 The "attitude to treatment questionnaire" that vou mention has to do with at titudes to discipline and organization, to the required degree of personal involvement with patients, to a formal versus an informal approach, to free communication, and to the fundamental scientific status of the work involved. Like doctors, nurses and patients differ radically between themselves on these issues, and the positions taken up are defended tenaciously and emotionally. ${ }^{1}$ Clearly very pervasive personality attributes are at issue.

The evidence suggests that doctors, nurses, and patients have the following characteristics in common. Those who adopt a scientific, physical, professional approach to psychiatric illness tend to adopt a traditionalis or "conservative" approach to many other aspects of life. They tend to be "outwardly" directed in their interests, preferring to deal with practical, concrete, realistic situations. They tend to be convergent thinkers, to use Liam Hudson's nomenclature. 5 That is, they prefer problems and situations that require a single correct answer for their solution.

On the other hand, staff and patients who adopt a psychological approach to psychiatric illness and treatment tend to be "liberal" or "revolutionary' in their apioroach to life. They are more "inwardly" directed in interest, preferring problems having to do with theories, philosophy, psychology, and religious mysticism. They are divergent thinkers in that they prefer situations or problems of a rather ambiguous kind lending themselves to more than one possible solution.

The treatment of psychiatric patients stretches the whole gamut of possibilities from the "revolutionary" socially oriented therapeutic community to the more "traditional" medically oriented physical treatments. The degree of active commitment and personal involvement on the part of the patient required in the treatment process varies considerably as one moves along the scale from psychotherapy to physical treatments In a somewhat similar way staff may be required to alter their attitudes and behaviour drastically in relation to the patient and each other as they move from a democratic to an authoritarian position.

Not all patients or all staff find these various treatment situations equally compatible. Our argument is that the more personally meaningful the situation is to both staff and patients, the more likely there is to be a successful therapeutic outcome. In order to achieve this match, more attention must be paid to staff and patient expectancies and underlying personality structure.-I am etc.,

P.ychology Department Woodford Bridge, Essex

Caine, T. M., in A Question of Attitudes, ed. D. Boorer, Appendix 1, p. 52. London, King Edward's Hospital Fund, Hospital Centre, 1970.
Caine, T. M. and Smail, D. I... The Treotment of Mental Il ness: Science, Faith and the Thera-
peutic Perconality. London, University of London Press, 1969.

Caine, T. M.. and Leigh, R., Britich fournal of Social and Clinical Psychology. 1972, 11.52. Caine. T. M.. Wiiesinghe, B.. and Woot. R. R. British Fournal of Psychiatry, 1973, 122. 87. Hudson, L., Contrary Imaginations. Harmondsworth, Penguin Books, 1966.

\section{Propellant a Factor in Asthma Deaths?}

SiR,-Dr. V. E. Archer (29 September, p 696) blames you (leading article, 25 November 1972, o. 443) and me (30 December 1972 , p. 795) for overlooking the "strong possibility" that the propellant in aerosol cans might have contributed to the increase in asthma deaths. Far from it: I did not mention this possibility because it has been investigated by quite a number of authors ${ }^{1-6}$ who have not found it strong but rather remote. Surnrisingly, Dr. Archer auotes some of these papers ${ }^{3-6}$ in his favour. He also wrongly implies that other propellants than fluorocarbons which have been used in the U.S.A. for "aerosol sniffing" with fatal effect have been used in asthma. In his support of Stolley's ${ }^{7}$ epidemiological theory about the reasons for the 1967 peak in asthma mortality in the U.K. he overlooks the fact that, in addition to other incongruities of this theory, the Australian data show no evidence whatever to support an epidemiological relationship between any aerosol and the observed mortality.$^{89}$-I am, etc.,

London N.3

H. HERXHEIMER

1 Dollery, C. T., Draffan, G. H., Davies, D. S., Paterson, J. W., Sudlow, M., and Walker, S. R. Lancet, 1971, 2, 565 .

Clark, D. G., and Tinston, D. J., Annals of Mullin, L. S., Azar, A., Reinhardt, C. F., Smith P., and Fabryka, E. F., American Industria Hygiene Association fournal, 1972, 33, 389.

Azar, A., Zapp, J. A., Reinhardt. C. F., and Stopps, G. J., Fournal of the American Medical Association, 1971, 215, 1501.

Brooks, S. M., Mintz, S., and Weiss, E. American

Stolley, P. D., American Review of Re-piratory Gandevia, B., Medical fournal of Australia, 1968,

$1,884$.
Gandevia, B., Medical fournal of Australia. In press.

\section{Increase in Asthma Mortality}

SIR, - The rise and subsequent decline of asthma mortality in England and Wales and a number of other countries has been discussed at length for several years, many of the most relevant articles appearing in the B.M.F. One explanation suggested for the increase in mortality was that resistance developed to the sympathomimetic bronchodilators in nebulizers and that a crossresistance to endogenous sympathetic stimulation could have led to a deterioration of the asthmatic state in patients using the nebulizers. ${ }^{1}$ The purpose of this letter is to question this hypothesis and to propose an epidemiological study (if such a study has not already been conducted) which might lead to an alternative hypothesis to explain the increase in asthma mortality observed in some countries.

It is clear that some asthmatic patients are unresnonsive to sympathomimetic ${\text { bronchodilators. }{ }^{2} 3}$ But it is important to determine whether the asthmatic patient deteriorated before he became resistant to these drugs or whether he first became resistant to the drugs and his asthmatic condition then deteriorated. If resistance to the bronchiolar effects of sympathomimetic drugs was observed in patients whose asthma was not deteriorating, it would be so apoarent that a large body of literature would have developed. Instead, there are reports ${ }^{4}$ of long term usage of isoprenaline in nebulizers without the development of resistance.

Harris $^{67}$ has reported that the use of bronchodilator nebulizers has had little or no effect on asthma mortality and that the maior problem is that patients have been inadequately treated as the course of their disease worsened. Bronchodilators are not indicated as sole therapy for severe asthma and are relatively ineffective when used, thus conveying the impression of rapidly developing resistance. Under such conditions, and when increased mucus is present, rigorous medical treatment is necessary (such as hydration, positive pressure breathing, aspiration of secretions, antibiotics, corticosteroids, etc.). Harris ${ }^{7}$ reported that the leading cause of death from asthma is mucus plugging of bronchi. Herxheimer, who has frequently reported on the resistance of asthmatic patients to sympathomimetic aerosols, stated: ${ }^{2}$ "If their asthma gets worse 
and they use their nebulizers every hour or so ... they become tolerant very quickly. . . . My standard practice is to regard this excessive use of the nebulizer as evidence of deteriorating asthma and therefore to increase the corticosteroid maintenance dose as soon as the number of inhalations exceeds 8-10 in 24 hours."

It would therefore be interesting to compare the increase in asthma mortality observed in some countries with the frequency and practice of using corticosteroids in asthmatic patients, since the reluctance on the part of many doctors to use steroids is well known and one-half of the asthmatics who died in Great Britain (1961-6) were found not to have been treated with steroids in their final illness. ${ }^{8}$ In support of the possibility that a decreased use of steroids was related to the increase in mortality rate is the finding of Gandevia ${ }^{9}$ that steroid prescriptions were decreased in one Australian state where the asthma mortality doubled and were two to three times greater in another state where the asthma mortality increased by only $50 \%$. After corticosteroids were introduced into England and Wales in 1952 the number of deaths due to asthma decreased progressively, from 1,879 in 1952 to 1,507 in 1957.10 Thus one wonders whether or not the use of steroids decreased in England and Wales from 1959 to 1966, when deaths due to asthma increased from 1,214 to 2,040 ?

Dollery stated ${ }^{11}$ about the situation in Britain that "there was roughly a doubling of hospital admissions from asthma .... after the warnings ... because physicians .. were recognizing that deteriorating asthma was a more serious condition than they had realized." These sentiments have also been expressed by Gandevia ${ }^{12}$ and Harris. ${ }^{7}$.- I am, etc.,

Department of Pharmacology,

Derling-Winthrop Recearch Institute,

Rensselaer, New York

1 Conolly, M., Davies, D. S., Dollery, C. T., and George, C. F., British fournal of Pharmacology,

$1971,43,389$.
2 Herxheimer, H., Lancet. 1969, 2, 642.
3 Herxheimer, H., British Medical fournal, 1972 , 4, 795 .

Sobol, B. J., Emirgil, C., Wadhwani, B., and Goyal, P., Anesthesia and Analgesia, 1972, 51, 21.

5 Ayres, S. M., Annals of Allergy, 1973, 31. 3.

6 Harris, M. C., Annals of Allergy, 1971, 29, 250

Harris, M. C. Annals of Allergy, 1972, 30. 315 . Speizer, F. E., Doll, R., Heaf, P., and Str L. B., British Medical fournal, 1968, 1. 339.
Gandevia, B., British Medical fournal, 1967, 2, 441 .

Speizer, F. E., Doll, R., and Heaf, P., British Medical fournal, 1968, 1, 335

1 Dollery. C. T., Annals of Allerey, 1973, 31. 38

2 Gandevia, B., Medical fournal of Australia, 1973 , $1,273$.

\section{Alcoholism Research}

SIR,-Government research policy in regard to alcoholism was brought up in the last paragraph of your leading article (22 September, p. 602) reviewing recent studies of outcome. At a time when the Department of Health and Social Security is devoting more attention to alcoholism than ever previously, I find your remarks a little unkind. Why should not a systematic follow-up of the research reviewed in your editorial find financial support from the D.H.S.S.? I guess that it would, as would "a systematic follow-through of ... any other research" be able to attract support from the D.H.S.S. or the Medical Research Council. There is a dearth of proposals for research in the field rather than a lack of support.

Government research policy seems to be no more "haphazard" with regard to alcoholism than could be said of any other field where many different avenues need pursuing, from enzyme studies in rats to social studies in Camberwell. Co-ordination between such disparate approaches must necessarily remain loose without deserving to be called "little integrated" and "haphazard." The D.H.S.S. is certainly very concerned with developing systems for monitoring alcoholism and is now jointly with the M.R.C. looking at potential research over the whole field. The addiction research unit at the Maudsley Hospital and the Institute of Psychiatry is largely funded by these two bodies and we continue to hope for knowledge from this source. It would be a pity, therefore, if you were to give readers the impression that the appropriate Government bodies were unconcerned with the problem of alcoholism research.-I am, etc.,

Department of Psychiatry

NeIl KeSSEI

University Hospital of South Manchester, Manchester

\section{Loud Knocking on the Back Door}

SIR,-I was somewhat taken aback to read in the B.M.F. (6 October, p. liii) a large and expensive advertisement in the personal columns headed "Consultant Surgeon." In this the advertiser openly solicited a medical school place for his son, whose "A" level grades were below the usual entry requirements of most medical schools.

That a reputable journal such as the B.M.F. accepted and published this advertisement, the nature of which must cause offence to many people, surprised me. Indeed, my colleagues and I found the wording of this piece so outrageous that we seriously doubted its authenticity.

I do not pretend that entrance to medical schools via the "back door" does not exist but never before have I seen it exhibited so blatantly. As the B.M.F. is regularly scanned by the general press, I should have thought that advertisements of this kind were inviting public criticism of both thi journal and the medical profession as a whole.-I am, etc.,

London N.3

JOHN SQUIRE Medical Student

\section{Intermediate Coronary Syndrome}

SIR,-I read with interest your leading article on this subject $(22$ September, $p$. 601). Referring to the use of anticoagulants in this condition it is stated: "The rationale of using these drugs is now doubtful and conflicts with modern observations on the low incidence of coronary thrombosis in myocardial infarction."

I have no argument with the first part of this statement but I must disagree with the last part. It is not my experience, or that of $\mathrm{my}$ colleagues, to find a low incidence of coronary thrombosis in fatal cases of myocardial ischaemia; in fact, the opposite is true. In 1970 Professor G. L. Montgomery and I published a paper ${ }^{1}$ on a two-year study of the cardiac lesions in fatal cases of myocardial ischaemia from the coronary care unit of the Edinburgh Royal Infirmary. Of 100 cases examined, coronary artery occlusions were found in 88, with thrombosis forming at least part of the occluding lesion in 71. Examination of a large number of similar cases from many sources over the subsequent years indicates no significant change in these figures.-I am, etc.,

University Medical School,

D. C. BouCH Edinburgh Bouch, D. C., and Montgomery, G. L., British
Heart fournal, 1970, 32, 795.

\section{Delayed Attacks of Malaria in Visitors to the Tropics}

SIR,-I have a high regard for Professor L. J. Bruce-Chwatt, but I am puzzled by some of his comments (22 September, p. 637) on the article by Dr. Paul Horstmann (25 August, p. 440). In particular, I do not understand his references to insufficient dosage or his reasons for saying that the suppressive dose given to Dr. Horstmann's subjects "was manifestly insufficient." The suppressive dose, $300 \mathrm{mg}$ of chloroquine base once weekly, was adequate to prevent any manifestation of malaria in 90 persons so long as it was being taken, and it seems to have been continued for about four weeks after the last probable exposure to infection. It is true that six of the 90 persons then developed attacks of vivax malaria after latent periods ranging from $7 \frac{1}{2}$ to 10 months, but surely this is, in Professor Bruce-Chwatt's own words, merely "a salutory reminder of the well-known fact that chemoprophylaxis with chloroquine must not be mistaken for causal prophvlaxis (especially when it comes to Plasmodium vivax)."

My own point of view on this subject can be stated briefly.

(1) The suppression of malaria with chloroquine alone is incapable of eradicating all $P$. vivax infections, whatever the suppressive dose used. Provided that the parasites are not drug-resistant, the continuation of dosage for four weeks after the last exposure to infection should eliminate the risk of an attack of falciparum malaria, but it will not prevent the possibility of an attack of vivax malaria.

(2) If an attack of vivax malaria does occur, the time interval between its onset and the cessation of suppressive dosage will be determined largely by the characteristics of the infecting strain of $P$. vivax. The strains typified by the New Guinea Chesson strain have a pattern of short latent intervals. and with one of these the attack is likely to occur within a few weeks; with Korean and other-mainly temperature zone-strain long latent neriods are common, and the attack may not occur for 6 to 14 months, though many will oocur at about 10 months. Between these two extremes there are other strains mainly in tropical areas, with latency patterns that are irregular and less well defined.

(3) In practice, therefore, vivax malaria must be considered as a possible cause of fever in anyone who has visited a malarious area during the previous 14 months or so especially if chloroquine or another 4aminoquinoline was used as the sole suppressive drug.

(4) Though not so relevant to the present discussion, it is worth noting that a radical 